\title{
Reativação do Citomegalovírus em Doentes com Sépsis numa Unidade de Cuidados Intensivos em Portugal
}

\author{
Cytomegalovirus Reactivation in Patients with Sepsis in \\ an Intensive Care Unit in Portugal
}

Paulo PAIXÃO $\triangle^{1,2}$, Patricia RAMOS ${ }^{1}$, Cátia PIEDADE ${ }^{2}$, André CASADO ${ }^{3}$, Maria CHASQUEIRA ${ }^{1}$

Acta Med Port 2020 Sep;33(9):576-582 - https://doi.org/10.20344/amp.12993

\begin{abstract}
RESUMO
Introdução: A reativação do citomegalovírus tem sido considerada um factor de agravamento nos doentes diagnosticados com sépsis nas unidades de Cuidados Intensivos. Os principais objetivos deste estudo consistiram na determinação da reativação do Cytomegalovirus em doentes internados numa unidade de Cuidados Intensivos com diagnóstico de sépsis, e se essa reativação estaria relacionada com a evolução do quadro clínico do doente.

Material e Métodos: Na presente investigação foram estudados 22 doentes, internados com o diagnóstico de sépsis na Unidade de Cuidados Intensivos do Hospital da Luz. A deteção do ácido desoxirribonucleico do citomegalovírus foi realizada por técnica de poly-

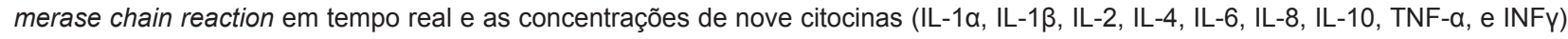
foram determinadas através de uma técnica de ELISA Multiplex.

Resultados: A reativação ocorreu em oito doentes (36,3\%). Não foram encontradas relações entre a reativação do citomegalovírus e o sexo, idade, tempo de permanência na unidade de Cuidados Intensivos, duração da ventilação mecânica e morte do doente. Também não foram encontradas diferenças significativas nas concentrações das citocinas nos doentes com e sem reativação. Contudo, os doentes com reativação do citomegalovírus apresentaram um maior tempo de internamento no hospital desde a entrada na unidade de Cuidados Intensivos até a alta hospitalar ou morte do doente $(p=0,025)$.

Discussão: Apesar da amostra de pequena dimensão, o presente estudo indicia que a reativação é um evento frequente nos doentes diagnosticados com sépsis e que pode estar relacionada com o prolongamento do tempo de permanência no hospital destes doentes. Conclusão: A análise conjunta dos resultados obtidos e da revisão da literatura não apoiam o conceito de que a monitorização do citomegalovírus deva ser implementada na prática clínica, mas parece prudente aguardarem-se por mais ensaios randomizados utilizando profilaxia antiviral, antes de se assumir uma atitude definitiva relativamente ao papel do citomegalovírus na sépsis.
\end{abstract}

Palavras-chave: Activação Viral; Citomegalovírus; Cuidados Intensivos; Portugual; Sépsis

\section{ABSTRACT}

Introduction: In the last few years, cytomegalovirus reactivation has been considered an aggravating factor for septic patients in Intensive Care units. The main objectives of this study were to determine cytomegalovirus reactivation in patients with a diagnosis of sepsis admitted to an intensive care unit, and whether this reactivation was related to the evolution of the patient's clinical condition.

Material and Methods: The detection of cytomegalovirus DNA was performed by real-time polymerase chain reaction and the concentration of nine cytokines (IL-1 $\alpha$, IL-1 $\beta$, IL-2, IL-4, IL-6, IL-8, IL- TNF- $\alpha$, and INFY) were determined by a Multiplex ELISA technique. Results: Eight of 22 septic patients (36.3\%) from the Intensive Care Unit of the Hospital da Luz had cytomegalovirus reactivation. No association was found between cytomegalovirus reactivation and gender, age, length of Intensive Care unit stay, duration of mechanical ventilation, and patient death. No significant differences were found in cytokine concentrations in patients with and without reactivation. However, patients with cytomegalovirus reactivation had a longer hospital stay from Intensive Care unit entry to hospital discharge or patient death $(p=0.025)$.

Discussion: Despite the low sampling rate, the present study suggests that reactivation is a frequent event in patients diagnosed with sepsis and may be related to prolonged hospital stay in these patients.

Conclusion: The overall analysis of the results obtained and the literature review do not support the concept that cytomegalovirus monitoring should be implemented in routine practice, but it seems prudent to wait for further randomized trials using antiviral prophylaxis, before assuming a definitive attitude towards the role of cytomegalovirus in sepsis.

Keywords: Critical Care; Cytomegalovirus; Portugal; Sepsis; Virus Activation

\section{INTRODUÇÃO}

$\mathrm{O}$ vírus citomegálico humano ou citomegalovirus (CMV) é um vírus da família Herpesviridae, sub-familia Betaherpesvirinae e género Cytomegalovirus, e é também conhecido como herpesvirus humano 5 (HHV-5). Após uma infecção primária, o CMV pode estabelecer um estado de latência com a expressão de um reduzido número de genes virais, sem causar qualquer dano na célula. ${ }^{1}$ Contudo, uma imunossupressão relacionada com o vírus da imuno- deficiência humana (VIH) ou com o transplante de órgãos pode reactivar o CMV do seu estado latente. .,3 $^{2}$ Também um estímulo nas células com CMV latente, como é o caso de um aumento de citocinas em circulação devido a um processo inflamatório (sépsis, queimaduras, traumas, cirurgias), pode reactivar este e inclusivamente outros vírus da família Herpesviridae, embora seja o CMV aquele que parece ter associação com a evolução do processo agudo. ${ }^{4-7}$

1. Unidade de Infeção. Chronic Diseases Research Centre - CEDOC. NOVA Medical School/Faculdade de Ciências Médicas. Universidade NOVA de Lisboa. Lisboa. Portugal.

2. Laboratório de Patologia Clínica - SYNLAB. Hospital da Luz. Lisboa. Portugal.

3. Unidade de Cuidados Intensivos. Hospital da Luz. Lisboa. Portugal.

$\square$ Autor correspondente: Paulo Paixão. paulo.paixao@nms.unl.pt

Recebido: 21 de outubro de 2019 - Aceite: 25 de maio de 2020 | Copyright @ Ordem dos Médicos 2020 
Ao ocorrer nestes doentes uma forte resposta pró-inflamatória, seguida de uma anti-inflamatória, desenvolve-se um ambiente propício à reativação do CMV, visto que os mediadores inflamatórios libertados pelas células do sistema imune são responsáveis pela ativação do complexo NF-KB e consequente ativação do promotor do gene IE do CMV. ${ }^{1,8,9}$ Por estas razões, os doentes das unidades de Cuidados Intensivos (UCI) têm sido recentemente reconhecidos como doentes em risco de infecção pelo CMV. Com efeito, publicações anteriores detetaram prevalências elevadas da infecção por CMV nestes doentes, relacionando ainda a presença do vírus com consequências graves no internamento, como o prolongamento do tempo de hospitalização, o aumento da duração da ventilação mecânica, o aumento da susceptibilidade a infecções nosocomiais, e, em alguns casos, a morte do doente..$^{5,10,11}$

Os principais objetivos deste estudo consistiram na determinação da reativação do CMV, em doentes internados numa unidade de Cuidados Intensivos com diagnóstico de sépsis, e se essa reativação estaria relacionada com a evolução do quadro clínico do doente ao longo do seu internamento no hospital. Esta evolução foi avaliada através da classificação Acute Physiology and Chronic Health disease Classification System II (APACHE II), do tempo de permanência na UCI e no hospital em geral, da necessidade e duração da ventilação mecânica e se houve óbito associado. Também se pretendeu determinar se a carga viral influenciou o estado clínico dos doentes e avaliou-se a análise da concentração de mediadores inflamatórios de cada doente durante a sua permanência no hospital e sua relação com a reativação do $\mathrm{CMV}$.

\section{MATERIAL E MÉTODOS \\ Doentes}

A investigação decorreu entre outubro de 2012 e julho de 2013 no Hospital da Luz, Lisboa - Portugal. Todos os doentes que deram entrada na Unidade de Cuidados Intensivos no Hospital da Luz com diagnóstico de sépsis e que consentiram em participar foram incluídos no estudo. ${ }^{12}$ Foram excluídos doentes imunodeprimidos (infeção VIH/SIDA ou por terapêutica imunossupressora) e grávidas.

Os dados clínicos recolhidos dos doentes foram: idade e sexo do doente, classificação APACHE II, data de admissão e saída da $\mathrm{UCI}$, necessidade e duração da ventilação mecânica e data da alta hospitalar ou, em alguns casos, data da morte do doente.

Os médicos assistentes não tiveram qualquer acesso aos resultados, sendo que estes foram utilizados apenas para fins de investigação.

O estudo foi aprovado pela Comissão de Ética do Hospital da Luz, tendo cada doente assinado o Consentimento Informado. Foram utilizadas para este estudo amostras que eram colhidas para a realização de análises de rotina solicitadas pelo médico assistente, pelo que este estudo não implicou colheita adicional de amostras aos doentes.

\section{Amostras}

As colheitas eram efetuadas semanalmente, iniciando-se ao quarto dia após o internamento. As amostras utilizadas foram soro, para serologia e citocinas, e sangue total em EDTA K3, para a técnica de amplificação de ácidos nucleicos polymerase chain reaction (PCR).

\section{Métodos analíticos}

Serologia: A deteção e quantificação dos anticorpos para o CMV foi efetuada pela metodologia ELFA (Enzyme Linked Fluorescent Assay, VIDAS, bioMérieux).

PCR: Sempre que um doente apresentava anticorpos IgG anti-CMV era efetuada a deteção e eventual quantificação do DNA do CMV pela técnica de PCR. A extração do ADN do CMV foi efetuada de acordo com o protocolo do fornecedor, utilizando-se $200 \mu \mathrm{L}$ de sangue total (kit de purificação JetQuick ${ }^{\circledR}$ Genomic DNA, Genomed, Löhne, Alemanha). A pesquisa do ADN do CMV foi efetuada com uma técnica de PCR em tempo real, dirigida para o gene UL83 do CMV (CMV HHV6,7,8 R-gene ${ }^{\text {TM }}$, ref:69-100, Argene, Biomérieux, Marcy-l'Etoile, França).

Um único resultado positivo por PCR foi considerado como diagnóstico de 'reativação'.

Para efeitos de deteção e quantificação e citocinas foi realizada a análise das citocinas em todos os doentes em que foi colhida mais que uma amostra através de uma técnica ELISA Multiplex para a pesquisa de 9 citocinas - IL-1 $\alpha$, IL$1 \beta$, IL-2, IL-4, IL-6, IL-8, IL-10, TNF- $\alpha$, e INFY (Q-Plex ${ }^{\mathrm{TM}} \mathrm{Ar}-$ ray Chemiluminescent, Quansys, Logan, Utah).

\section{Tratamento estatístico}

Os dados obtidos ao longo do estudo foram analisados recorrendo ao software SPSS (versão16.0). Para além de métodos estatísticos descritivos (média e desvio padrão) e do teste de Shapiro Wilk foram também utilizados testes paramétricos (teste $t$ de student, teste $t$ para amostras emparelhadas, correlação de Pearson) e não paramétricos (teste $U$ de Mann-Whitney, teste exacto de Fisher, teste de Wilcoxon, correlação de Spearman). Diferenças entre as variáveis estudadas foram consideradas significativas na presença de um valor de $p<0,05$.

\section{RESULTADOS \\ Doentes diagnosticados com sépsis}

Nos meses do estudo deram entrada na $\mathrm{UCl}$ um total de 740 doentes, dos quais 27 doentes com o diagnóstico de sépsis. Contudo, cinco doentes foram excluídos: um por não assinar o consentimento informado, dois por serem imunodeprimidos e dois por apresentarem serologia negativa para o CMV. Dos restantes 22 doentes com IgG anti-CMV positiva foram recolhidas 59 amostras (média $=2,73$; mín $=1$; máx $=5$ ). Dos doentes em estudo, com idades compreendidas entre os 44 e os 85 anos, 15 eram do sexo masculino. Três doentes foram diagnosticados com choque séptico e em oito ocorreu falência de pelo menos um órgão. A classificação APACHE II foi em média de 21,86 (mín = 14 ; máx $=34$ ), com os doentes a permaneceram em média 
11,93 dias ( mín = 1,10; máx $=52,40$ ) internados na UCl. Quanto ao tempo de internamento hospitalar a média foi de 21,82 dias, sendo o período mínimo e máximo de permanência no hospital de 5 e 50 dias, respetivamente. Dezasseis doentes tiveram necessidade de ventilação mecânica com uma duração média de 10,07 dias (mín = 0,17; máx $=43,92$ ). Dos vinte e dois doentes, três faleceram durante o seu internamento na $\mathrm{UCl}$, outros quatro faleceram após transferência para outros serviços do hospital (Tabela 1).

\section{Infeção ativa por CMV}

Foi feita a pesquisa do ADN do CMV em 59 amostras, correspondentes a 22 doentes, tendo sido detetado em 12 $(12 / 59)$, correspondentes a oito doentes. Assim, considerou-se que a taxa de reativação do $\mathrm{CMV}$ nestes doentes foi de $36,4 \%$, ou seja, 8 em 22 doentes tiveram pelo menos um resultado positivo por PCR e como tal tiveram o diagnóstico de reativação por CMV. Esta deteção ocorreu em média após 16 dias de internamento (mín = 3; máx $=39$ ), tendo sido encontrada em três doentes logo na primeira amostra analisada. Em três doentes a reativação do CMV ocorreu após transferência da UCl para outros serviços hospitalares. Se se tiver em conta a reativação do CMV apenas durante o internamento na $\mathrm{UCl}$, esta ocorreria em média ao fim de 9,2 dias de permanência do doente na $\mathrm{UCl}$ (mín =
3; máx $=22$ ). Dos oito doentes com reativação, três tiveram alta e três faleceram provavelmente ainda com infeção ativa pelo vírus, dado que o ADN do CMV estava presente nas últimas amostras colhidas a estes doentes.

Quando comparados os dados obtidos dos doentes com a reativação do CMV ao longo do seu internamento (Tabela 1), apenas foi detetada uma diferença significativa nos dias de internamento hospitalar, sendo que os doentes com reativação do CMV têm um maior tempo de hospitalização que os doentes sem reativação $(30,25$ vs 17 dias. $p$ $=0,025)$.

Para determinar se a carga viral influencia o estado clínico do doente, procedeu-se à comparação dos dados recolhidos durante a investigação entre os doentes que obtiveram uma carga inferior a 1000 cópias de ADN de CMV por $\mathrm{ml}$ durante a reativação $(n=5 ; 62,5 \%)$ e os doentes que obtiveram uma carga viral superior a 1000 cópias de ADN por CMV por $\mathrm{mL}(\mathrm{n}=3 ; 37,5 \%)$ (Tabela 2$)$. Contudo nenhuma diferença significativa foi encontrada, à semelhança da análise do quadro clínico dos doentes com reativação, tendo em conta o pico da carga viral que atingiram ao longo do seu internamento (Tabela 3).

\section{Deteção e quantificação das citocinas}

Das nove citocinas estudadas em 16 doentes, apenas

Tabela 1 - Comparação das características do estado clínico dos doentes tendo em conta a reativação do CMV

\begin{tabular}{|c|c|c|c|c|c|}
\hline & & \multicolumn{4}{|c|}{ Reativação } \\
\hline & & Total de doentes & $\underset{(n=8)}{\operatorname{Sim}}$ & $\begin{array}{c}\text { Não } \\
(n=14)\end{array}$ & Valor-p \\
\hline \multirow{2}{*}{ Sexo } & Masculino & 15 & 5 & 10 & \multirow{2}{*}{1} \\
\hline & Feminino & 7 & 4 & 3 & \\
\hline \multicolumn{2}{|l|}{$\begin{array}{l}\text { Idade: Média } \\
\text { (mín; máx) }\end{array}$} & $\begin{array}{c}68,82 \\
(44 ; 85)\end{array}$ & $\begin{array}{c}72,75 \\
(53 ; 85)\end{array}$ & $\begin{array}{c}66,57 \\
(44 ; 82)\end{array}$ & $0,330^{* *}$ \\
\hline \multicolumn{2}{|c|}{ APACHE II à entrada do estudo } & $\begin{array}{c}21,86 \\
(14 ; 34)\end{array}$ & $\begin{array}{c}21 \\
(14 ; 30)\end{array}$ & $\begin{array}{c}22,36 \\
(16 ; 34)\end{array}$ & $0,607^{* * *}$ \\
\hline \multicolumn{2}{|c|}{$\begin{array}{l}\text { Duração do internamento hospitalar } \\
\text { [Média de dias (mín; máx)] }\end{array}$} & $\begin{array}{l}21,82 \\
(5 ; 50)\end{array}$ & $\begin{array}{c}30,25 \\
(10 ; 44)\end{array}$ & $\begin{array}{c}17 \\
(5 ; 50)\end{array}$ & $0,025^{* * *}$ \\
\hline \multicolumn{2}{|c|}{$\begin{array}{l}\text { Duração do internamento na UCI } \\
\text { [Média de dias (mín; máx)] }\end{array}$} & $\begin{array}{c}11,93 \\
(1,10 ; 52,40)\end{array}$ & $\begin{array}{c}11,48 \\
(2,50 ; 30,50)\end{array}$ & $\begin{array}{c}12,20 \\
(1,10 ; 52,40)\end{array}$ & $0,973^{* *}$ \\
\hline \multirow{2}{*}{ Ventilação mecâ } & Sim & 16 & 7 & 9 & \multirow{2}{*}{$0,351^{*}$} \\
\hline & Não & 6 & 1 & 5 & \\
\hline \multicolumn{2}{|c|}{$\begin{array}{l}\text { Duração da ventilação mecânica } \\
\text { [Média de dias (mín; máx)] }\end{array}$} & $\begin{array}{c}10,07 \\
(0,17 ; 43,92)\end{array}$ & $\begin{array}{c}8,22 \\
(0,17 ; 2633)\end{array}$ & $\begin{array}{c}11,52 \\
(0,63 ; 43,92)\end{array}$ & $0,681^{* *}$ \\
\hline $\begin{array}{l}\text { Morte do doente } \\
(n=20)\end{array}$ & Não & 13 & 5 & 8 & $1^{*}$ \\
\hline
\end{tabular}

${ }^{*}$ : Teste de Fisher; ${ }^{* *}$ : Teste de Mann-Whitney; ***: Teste $t$ de student 
Tabela 2 - Comparação das características do estado clínico dos doentes tendo em conta a carga viral do doente

\begin{tabular}{|c|c|c|c|c|}
\hline & & $\begin{array}{l}\text { Doentes com carga viral > } 1000 \\
\text { cópias de ADN de CMV } / \mathrm{mL} \\
\qquad(n=3)\end{array}$ & $\begin{array}{l}\text { Doentes com carga viral }<1000 \\
\text { cópias de ADN de CMV } / \mathrm{mL} \\
\qquad(n=5)\end{array}$ & Valor-p \\
\hline \multicolumn{2}{|l|}{ APACHE II } & $\begin{array}{c}20,33 \\
(14 ; 26)\end{array}$ & $\begin{array}{c}21,40 \\
(14 ; 30)\end{array}$ & $0,824^{*}$ \\
\hline \multirow{2}{*}{ Ventilação mecânica } & Sim & 2 & 5 & \multirow{2}{*}{$0,375^{*}$} \\
\hline & Não & 1 & 0 & \\
\hline \multicolumn{2}{|c|}{$\begin{array}{l}\text { Duração da ventilação mecânica } \\
\text { [Média (mín; máx)] }\end{array}$} & $\begin{array}{c}14,56 \\
(2,79 ; 26,33)\end{array}$ & $\begin{array}{c}5,68 \\
(0,17 ; 11,29)\end{array}$ & $0,277^{* *}$ \\
\hline \multicolumn{2}{|c|}{$\begin{array}{l}\text { Tempo de internamento na UCI } \\
\text { [Média (mín; máx)] }\end{array}$} & $\begin{array}{c}13,70 \\
(3,50 ; 30,50)\end{array}$ & $\begin{array}{c}10,14 \\
(2,50 ; 21,90)\end{array}$ & $0,727^{* *}$ \\
\hline \multicolumn{2}{|c|}{$\begin{array}{l}\text { Tempo de internamento hospitalar } \\
\text { [Média (mín; máx)] }\end{array}$} & $\begin{array}{c}26,33 \\
(17 ; 32)\end{array}$ & $\begin{array}{c}32,60 \\
(10 ; 44)\end{array}$ & $0,447^{* *}$ \\
\hline \multirow{2}{*}{ Morte do Doente } & Sim & 2 & 1 & \multirow{2}{*}{$0,464^{*}$} \\
\hline & Não & 1 & 4 & \\
\hline
\end{tabular}

*: Teste de Fisher; **: Teste $t$ de student

seis foram detetadas em todos os doentes: IL-1 $1>0,3 \mathrm{pg} /$ $\mathrm{mL}), \mathrm{IL}-4$ (> 0,2 pg/mL), IL-6 (> 0,6 pg/mL), IL-8 (>0,4 pg/ $\mathrm{mL}), \mathrm{IL}-10$ (> 0,3 pg/mL) e TNF- $\alpha$ (> 1,4 pg/mL). A IL-2 não foi detetada em nenhuma das amostras analisadas, tendo a sua concentração sido sempre inferior ao limite de deteção da técnica, enquanto as concentrações da IL-1 $1 \alpha$ e do INFy em apenas metade das amostras estudadas apresentaram valores acima do limite de deteção mas inferiores ao limite de quantificação, pelo que não foi possível a sua utilização na comparação nos doentes com e sem reativação do CMV.

Procedeu-se à comparação das concentrações das citocinas nos doentes com e sem reativação do CMV nas amostras colhidas à entrada e após duas semanas, dado que a reativação do CMV ocorreu em média na segunda semana de internamento. Não se verificaram diferenças estatisticamente significativas entre os dois grupos quer à entrada (Tabela 3), quer passadas duas semanas (Tabela
4). Nos doentes sem reativação do CMV, a concentração das citocinas diminuíram, com exceção da IL-4 (médias de 2,93 e 2,96, respetivamente à entrada e às duas semanas) e da IL-8 (80,11 e 83,63). Nas que tiveram diminuição, apenas duas apresentam uma diferença estatisticamente significativa, a IL-6 ( $p=0,023)$ e IL-10 $(p=0,043)$. Nos doentes com reativação, houve três citocinas que diminuíram e três que aumentaram, mas sem diferenças estatisticamente significativas.

\section{DISCUSSÃO}

Que seja do nosso conhecimento, este é o primeiro trabalho efetuado em Portugal sobre a relação da sépsis com a infeção por CMV.

Os resultados obtidos com o presente estudo estão de acordo com publicações anteriores, que descrevem como frequente a reativação do CMV em doentes internados em unidades de cuidados intensivos. Considerando como

Tabela 3 - Comparação das concentrações das citocinas nos doentes com e sem reativação do CMV nas amostras colhidas à entrada

\begin{tabular}{|c|c|c|c|c|c|}
\hline & \multicolumn{2}{|c|}{$\begin{array}{l}\text { Doentes com reativação do CMV } \\
\qquad(\mathrm{n}=8)\end{array}$} & \multicolumn{2}{|c|}{$\begin{array}{l}\text { Doentes sem reativação do CMV } \\
\qquad(n=8)\end{array}$} & \multirow{2}{*}{ Valor- $p$} \\
\hline & Média $(\mathrm{pg} / \mathrm{mL})$ & Mínimo - Máximo & Média $(\mathrm{pg} / \mathrm{mL})$ & Mínimo - Máximo & \\
\hline IL-1 $\beta$ & 22,80 & $12,42-58,16$ & 18,10 & $15,89-20,22$ & $0,721^{*}$ \\
\hline IL-4 & 2,66 & $0,20-4,12$ & 2,85 & $2,75-3,00$ & $0,798^{*}$ \\
\hline IL-6 & 96,15 & $8,26-244,59$ & 57,98 & $8,57-116,73$ & $0,878^{*}$ \\
\hline IL-8 & 82,10 & $19,55-197,48$ & 80,35 & $20,14-232,56$ & $0,959^{*}$ \\
\hline IL-10 & 9,55 & $6,10-15,65$ & 13,54 & $5,81-55,25$ & $0,721^{*}$ \\
\hline TNF- $\alpha$ & 22,34 & $9,78-56,54$ & 23,38 & $7,42-69,05$ & $0,878^{*}$ \\
\hline
\end{tabular}


Tabela 4 - Comparação das concentrações das citocinas nos doentes com e sem reativação do CMV nas amostras colhidas após duas semanas

\begin{tabular}{|c|c|c|c|c|c|}
\hline & \multicolumn{2}{|c|}{$\begin{array}{l}\text { Doentes com reativação do CMV } \\
\qquad(n=6)\end{array}$} & \multicolumn{2}{|c|}{$\begin{array}{l}\text { Doentes sem reativação do CMV } \\
\qquad(n=8)\end{array}$} & \multirow[t]{2}{*}{ Valor-p } \\
\hline & Média (pg/mL) & Mínimo - Máximo & Média (pg/mL) & Mínimo - Máximo & \\
\hline $\mathrm{IL}-1 \beta$ & 20,22 & $16,76-29,17$ & 18,09 & $17,10-19,80$ & $0,491^{*}$ \\
\hline $\mathrm{IL}-4$ & 3,03 & $2,83-3,29$ & 2,90 & $2,72-3,42$ & $0,142^{*}$ \\
\hline IL-6 & 56,18 & $9,02-114,86$ & 20,27 & $7,51-42,88$ & $0,282^{*}$ \\
\hline IL-8 & 123,00 & $24,41-285,16$ & 54,11 & $10,21-94,51$ & $0,228^{*}$ \\
\hline IL-10 & 7,39 & $0,30-15,83$ & 4,21 & $0,30-7,66$ & $0,218^{* *}$ \\
\hline TNF- $\alpha$ & 23,74 & $9,09-59,04$ & 12,64 & $9,27-19,58$ & $0,181^{*}$ \\
\hline
\end{tabular}

*: Teste U de Mann-Whitney; **: Teste $t$ de student

reativação a evidência de infeção ativa (PCR positiva), a taxa de reativação neste estudo foi de $36,4 \%$ (8/22), encontrando-se dentro dos valores obtidos por outras equipas que estudaram a reativação do CMV em doentes com sépsis, e que obtiveram valores compreendidos entre $8,5 \%$ - $45 \%{ }^{13,14} \mathrm{~A}$ grande variabilidade observada nos resultados obtidos com os diferentes estudos prende-se com variados fatores, nomeadamente com a seroprevalência da população estudada (alguns trabalhos apenas estudam os doentes seropositivos para o CMV, enquanto outros englobam também os seronegativos), com diferenças nos graus de gravidade dos doentes das diferentes populações, na frequência com que se pesquisa o CMV (desde uma única colheita até duas colheitas por semana, aumentando naturalmente a taxa de deteção com o número de colheitas), nas técnicas (antigenémia e/ou cultura e/ou PCR, sendo a última a mais sensível) e no tipo de amostras utilizadas (sangue isoladamente ou em combinação com amostras respiratórias e/ou urina). No entanto, a maioria dos estudos com um desenho idêntico ao nosso tiveram taxas de deteção perto dos $30 \%-40 \%$, o que, conjuntamente com os resultados obtidos neste estudo, nos permite sugerir que cerca de um terço dos doentes com sépsis e internados em $\mathrm{UCl}$ terão uma reativação do CMV, se a sua estadia nesta unidade se estender o tempo suficiente para a sua expressão.

O tempo médio (em mediana) para esta expressão foi, no presente estudo, de 13 dias de internamento, embora os limites se situassem entre 3 e 39 dias. Comparando com a literatura, verificamos que a mediana para a primeira deteção, nos diferentes estudos, situa-se entre 4 e 28 dias, embora com a utilização da PCR este intervalo diminua para 4 a 12 dias. ${ }^{15}$ Desta forma, a mediana no nosso estudo situou-se ligeiramente acima deste último intervalo, mas encontrando-se ainda assim dentro do esperado para a metodologia utilizada no presente ensaio, a técnica da PCR e com uma amostra semanal. Eventualmente, a execução de duas colheitas por semana, como alguns estudos efetuaram, ${ }^{4,16}$ poderá ter contribuído para ligeiras diminuições das medianas, quando comparadas com a do nosso estudo.

Relativamente às consequências clínicas das reativações, a maioria dos estudos que envolveram exclusivamente doentes com sépsis documentaram associação da infeção por CMV com o prolongamento da ventilação mecânica e da estadia na UCl. ${ }^{10,11}$ No presente estudo encontrou-se uma diferença significativa nos dias de internamento hospitalar, sendo que os doentes com reativação do CMV tiveram um maior tempo de hospitalização que os doentes sem reativação. Apesar de haver a possibilidade desta associação dever-se simplesmente a uma maior oportunidade para detetar a infeção por CMV nos doentes que permanecem mais tempo internados, parecem existir provas convincentes de que efetivamente o CMV poderá estará ligado ao prolongamento da estadia hospitalar. ${ }^{17}$ A relação com o prolongamento da ventilação não foi, no entanto, encontrada no nosso estudo, embora ele encontre, inclusivamente, suporte em estudos experimentais que demonstraram que a reativação do CMV em ratos imunocompetentes pode causar lesão pulmonar e que esta lesão pode inclusivamente ser prevenida com a administração de antivirais. ${ }^{18}$

Também a associação com o aumento da mortalidade não foi demonstrada no nosso estudo, o que está de acordo com alguns estudos que englobaram só doentes com o diagnóstico de sépsis. ${ }^{13}$ No entanto, esta associação é descrita noutros estudos, sendo possível que as disparidades observadas estejam simplesmente relacionadas com o baixo poder estatístico e/ou com o enviesamento na seleção dos doentes em alguns dos estudos. ${ }^{19}$

Deve ser enfatizado que a associação verificada no nosso estudo, tal como as associações verificadas nos estudos anteriormente mencionados, não provam a causalidade do CMV, podendo este ser apenas um marcador de gravidade na sépsis, em vez de fator de agravamento, tal como acontece com outros membros da família Herpesviridae, que também reativam com frequência na sépsis. ${ }^{7}$ No entanto, deve ser relembrado que o CMV tem um papel patogénico há muito reconhecido nas reativações em indivíduos imunodeprimidos, ${ }^{2,3}$ pelo que assume primordial 
importância o esclarecimento do eventual papel deste vírus. Desta forma, apenas ensaios randomizados para prevenção ou tratamento do CMV, no contexto de sépsis, poderão dar uma resposta definitiva a esta questão. Neste sentido, deve ser referido que num estudo randomizado, que incluía doentes imunocompetentes com sépsis, o ganciclovir ao ser dado profilaticamente e quando comparado com placebo, não teve o efeito desejado de redução na duração da ventilação mecânica, na incidência de bacteriémia e fungémia secundárias, no tempo de estadia na $\mathrm{UCI}$, na mortalidade ou na diminuição da IL-6 ao $14^{\circ}$ dia, este último um dos objetivos pretendidos neste estudo. ${ }^{20}$ Desta forma, e embora mais estudos sejam necessários para se retirarem conclusões definitivas, a possibilidade de se tratar apenas de um marcador de gravidade, parece ser a mais plausível de momento.

Antes de se analisarem as potenciais alterações provocadas pelo CMV nas moléculas inflamatórias, deve referir-se que a sépsis, por si só, já é responsável por alterações profundas nos valores das citocinas, independentemente de haver ou não reativação do CMV concomitantemente. Com efeito, noutros estudos já se observaram diferenças significativas, em várias citocinas (IL-1ß, IL-4, IL-6, IL-8, IL10 , TNF- $\alpha$ ), entre doentes com e sem sépsis. ${ }^{21,22}$

A relação da reativação pelo $\mathrm{CMV}$ com algumas moléculas inflamatórias em doentes com sépsis também já objeto de vários estudos, quer experimentais, com animais de laboratório, quer com populações de doentes com sépsis e com ou sem reativação por CMV. Relativamente aos primeiros, foi demonstrado que tanto o lipopolissacárido das bactérias de Gram negativo, ${ }^{8}$ como o TNF- $\alpha$, a IL-1 $\beta(1,9)$ e a IL-6 conseguem reativar o vírus da sua forma latente. ${ }^{23}$

Vários estudos realizados em doentes com sépsis, ainda na década de 90 , permitiram a primeira comparação das concentrações de IL-6, IL-1 e TNF- $\alpha$ obtidas durante o internamento dos doentes com sépsis que reativaram o $\mathrm{CMV}$, com as dos doentes hospitalizados com sépsis mas sem reativação viral. Esses estudos mostraram que as concentrações de TNF- $\alpha$ e IL-1 $\beta$ encontravam-se mais elevadas nos doentes que reativaram o vírus. ${ }^{4}$ Outras alterações têm sido igualmente encontradas, como uma diminuição na secreção pelas Killer cells antes dos episódios de reativação do CMV, um aumento da IL-10 e da IL-15 a preceder a reativação, ${ }^{24}$ ou a IL-10 marginalmente elevada na reativação. ${ }^{10}$

No presente trabalho foram avaliadas nove moléculas inflamatórias, constituindo assim uma das publicações com maior número de citocinas estudadas em doentes com sépsis e infeção por CMV. Na comparação das concentrações das citocinas nos doentes com e sem reativação do CMV, nas amostras colhidas à entrada e após duas semanas do estudo, apesar de não terem sido encontradas diferenças estatisticamente significativas, existe uma tendência para uma maior concentração em todas as citocinas nos doentes com reativação após as duas semanas de internamento. Ao analisar-se a evolução nas duas semanas, verificou-se que nos doentes sem reativação do CMV, com exceção da IL-4 e da IL-1 $\beta$ que se mantiveram estáveis, as concentrações das outras citocinas diminuíram, e em duas delas esta diferença foi mesmo estatisticamente significativa, nomeadamente a IL-6 $(p=0,023)$ e a IL-10 $(p=0,043)$. Nos doentes com reativação, apenas houve diminuição acentuada da concentração com a IL-6, mas sem atingir valores estatisticamente significativos. A diminuição desta citocina, tal como da II-8, tem sido associada a melhor prognóstico em doentes com a síndroma da dificuldade respiratória aguda (SDRA), sendo mesmo colocada a hipótese de que uma intervenção a nível destas citocinas poderia ter impacto na mortalidade. Com efeito, na sépsis os elevados níveis de IL-6 tem um papel relevante na denominada 'tempestade de citocinas', com alguns trabalhos a sugerirem que o bloqueio desta citocina poderá ter efeitos benéficos na evolução clínica. ${ }^{25}$ A diminuição da IL-6 no nosso estudo sugere, desta forma, que uma melhoria clínica pode ter ocorrido entre a primeira e a segunda colheitas, embora o número de doentes envolvidos não permita confirmar esta possibilidade.

No caso da IL-8, a sua indução é descrita como particularmente importante durante a infeção por CMV, uma vez que os neutrófilos são atraídos pela IL-8 e desempenham um papel importante na disseminação do vírus. Para além disso, a IL-8 tem um efeito positivo na replicação do CMV. ${ }^{26}$ Estes dados estão de acordo com o verificado no presente trabalho, dado que foi com a IL-8 que se verificou a diferença mais marcada, tendo evoluído em sentidos opostos nos doentes com e sem reativação, com subida nos doentes com reativação mas descida nos doentes sem reativação.

Embora a IL-10 seja uma citocina anti-inflamatória e, como anteriormente referido, poder encontrar-se uma justificação para se encontrar marginalmente elevada na reativação, ${ }^{10}$ tal não foi encontrado no presente trabalho, embora se tenha verificado uma diminuição menos acentuada à segunda semana, quando comparada com a diminuição nos doentes sem reativação.

À semelhança de um outro estudo recentemente publicado, ${ }^{27}$ não foi possível tirar conclusões sobre as evoluções do INFY, uma vez que os resultados obtidos no presente estudo eram inferiores ao limite de quantificação.

É importante salientar que a amostra de pequena dimensão do presente estudo condiciona as conclusões que se possam retirar do mesmo, devendo estas ilações serem apenas consideradas como sugestivas, dadas as limitações deste estudo.

\section{CONCLUSÃO}

Os resultados obtidos no presente estudo reforçam a ideia de que a reativação por CMV pode estar associada ao prolongamento do internamento hospitalar em doentes com sépsis, mas não se verificaram outras consequências clínicas, tal como reportado por outros.

A análise conjunta dos resultados obtidos e da revisão da literatura não suportam o conceito de que a monitorização do CMV deva ser implementada na rotina, mas parece prudente aguardarem-se mais ensaios randomizados 
utilizando profilaxia antiviral, antes de se assumir uma atitude definitiva relativamente ao papel do CMV na sépsis.

\section{PROTEÇÃO DE PESSOAS E ANIMAIS}

Os autores declaram que os procedimentos seguidos estavam de acordo com os regulamentos estabelecidos pelos responsáveis da Comissão de Investigação Clínica e Ética e de acordo com a Declaração de Helsínquia da Associação Médica Mundial.

\section{CONFIDENCIALIDADE DOS DADOS}

Os autores declaram ter seguido os protocolos do seu centro de trabalho acerca da publicação de dados.

\section{CONFLITOS DE INTERESSE}

Os autores declaram não ter conflitos de interesses relacionados com o presente trabalho.

\section{FONTES DE FINANCIAMENTO}

Este trabalho não recebeu qualquer tipo de suporte financeiro de nenhuma entidade no domínio público ou privado.

al. Cytomegalovirus reactivation and associated outcome of critically ill patients with severe sepsis. Critical Care. 2011;15:R77.

14. Jain $M$, Duggal $S$, Chugh TD. Cytomegalovirus infection in nonimmunosuppressed critically ill patients. J Infect Dev Ctries. 2011;5:5719.

15. Osawa R, Singh N. Cytomegalovirus infection in critically ill patients: a systematic review. Crit Care. 2009;13:R68.

16. von Müller L, Klemm A, Weiss $M$, Schneider $M$, Suger-Wiedeck $H$, Durmus $\mathrm{N}$, et al. Active cytomegalovirus infection in patients with septic shock. Emerg Infect Dis. 2006;12:1517-22.

17. Limaye A, Kirby K, Rubenfeld G, Leisenring W, Bulger E, Neff M, et al. Cytomegalovirus reactivation in critically-ill immunocompetent patients. JAMA. 2008;300:413-22.

18. Cook $\mathrm{CH}$, Zhang $\mathrm{Y}$, Sedmak DD, Martin LC, Jewell S, Ferguson RM. Pulmonary cytomegalovirus reactivation causes pathology in immunocompetent mice. Crit Care Med. 2006;34:842-9.

19. Kalil AC, Florescu DF. Is cytomegalovirus reactivation increasing the mortality of patients with severe sepsis? Crit Care. 2011;15:138.

20. Limaye AP, Stapleton RD, Peng L, Gunn SR, Kimball LE, Hyzy R, et al. Effect of ganciclovir on IL-6 levels among cytomegalovirusseropositive adults with critical illness: a randomized clinical trial. JAMA. 2017;318:731-40.

21. Ulloa L, Tracey KJ. The "cytokine profile": a code for sepsis. Trends Mol Med. 2005;11:56-63.

22. Netea MG, van der Meer JW, van Deuren M, Kullberg BJ. Proinflammatory cytokines and sepsis syndrome: not enough, or too much of a good thing? Trends Immunol. 2003;24:254-8.

23. Reeves MB, Compton T. Inhibition of inflammatory interleukin- 6 activity via extracellular signal-regulated kinase-mitogen-activated protein kinase signaling antagonizes human cytomegalovirus reactivation from dendritic cells. J Virol. 2011;85:12750-8.

24. Chiche L, Forel JM, Thomas G, Farnarier C, Cognet C, Guervilly C, et al. Interferon- $y$ production by natural killer cells and cytomegalovirus in critically ill patients. Crit Care Med. 2012;40:3162-9.

25. Tanaka T, Narazaki M, Kishimoto T. Immunotherapeutic implications of IL-6 blockade for cytokine storm. Immunotherapy. 2016;8:959-70.

26. Costa H, Nascimento R, Sinclair J, Parkhouse RM. Human cytomegalovirus gene UL76 induces IL-8 expression through activation of the DNA damage response. PLoS Pathog. 2013;9:e1003609.

27. van de Groep K, Nierkens S, Cremer OL, Peelen LM, Klein Klouwenberg $\mathrm{PM}$, Schultz MJ, et al. Effect of cytomegalovirus reactivation on the time course of systemic host response biomarkers in previously immunocompetent critically ill patients with sepsis: a matched cohort study. Crit Care. 2018;22:348. 